\title{
Genomics and epidemiology for gastric adenocarcinomas (GE4GAC): a Brazilian initiative to study gastric cancer
}

GE4GAC group, Thais F. Bartelli', Lais L. Senda de Abrantes², Helano C. Freitas ${ }^{1,18}$, Andrew M. Thomas ${ }^{1,3,4}$, Jordana M. Silva', Gabriela E. Albuquerque1, Luiza F. Araújo', Gabriela P. Branco', Maria G. de Amorim', Marianna S. Serpa', Isabella K. T. M. Takenaka', Deborah T. Souza', Lucas O. Monção', Bruno S. Moda', Renan Valieris ${ }^{5}$, Alexandre Defelicibus ${ }^{5}$, Rodrigo Borges ${ }^{5}$, Rodrigo D. Drummond ${ }^{5}$, Francisco I. A. Alves ${ }^{6}$, Monize N. P. Santos ${ }^{5}$, Irina G. Bobrovnitchaia ${ }^{5}$, Eran Elhaik, Luiz G. V. Coelho ${ }^{8}$, André Khayat ${ }^{9}$, Samia Demachki ${ }^{10}$, Paulo P. Assumpção ${ }^{10}$, Karina M. Santiago ${ }^{11}$, Giovana T. Torrezan ${ }^{11}$, Dirce M. Carraro ${ }^{11}$, Stela V. Peres ${ }^{12}$, Vinícius F. Calsavara ${ }^{12}$, Rommel Burbano ${ }^{13,10}$, Calebe R. Nóbrega ${ }^{12}$, Graziela P. P. Baladão ${ }^{12}$, Ana C. C. Pereira ${ }^{12}$, Camila M. Gatti ${ }^{12}$, Marcela A. Fagundes ${ }^{10}$, Marília S. Araújo ${ }^{10}$, Tayana V. Miranda ${ }^{9}$, Monica S. Barbosa ${ }^{14}$, Daniela M. M. Cardoso ${ }^{14}$, Lilian C. Carneiro ${ }^{14}$, Alexandre M. Brito ${ }^{15}$, Amanda F. P. L. Ramos ${ }^{14}$, Lucas L. L. Silva ${ }^{14}$, Jaqueline C. Pontes ${ }^{14}$, Tatiane Tiengo ${ }^{12}$, Paola E. Arantes ${ }^{12}$, Vilma Santana ${ }^{16}$, Milena Cordeiro ${ }^{16}$, Rosane O. Sant'Ana ${ }^{17}$, Hanna B. Andrade ${ }^{17}$, Ana K. M. Anaissi ${ }^{10}$, Sara V. Sampaio ${ }^{17}$, Emne A. Abdallah², Ludmilla T. D. Chinen², Alexcia C. Braun², Bianca C. T. Flores², Celso A. L. Mello ${ }^{18}$, Laura C. L. Claro ${ }^{19}$, Claudia Z. Sztokfisz ${ }^{20}$, Carlos C. Altamirano ${ }^{21}$, David R. F. Carter ${ }^{22}$, Victor H. F. Jesus ${ }^{18}$, Rachel Riechelmann ${ }^{18}$, Tiago Medina ${ }^{23}$, Kenneth J. Gollob ${ }^{23}$, Vilma R. Martins ${ }^{24}$, João C. Setúbal ${ }^{4}$, Adriane G. Pelosof ${ }^{20}$, Felipe J. Coimbra ${ }^{25}$, Wilson L. Costa-Jr ${ }^{25}$, Israel T. Silva ${ }^{5}$, Diana N. Nunes ${ }^{1}$, Maria P. Curado ${ }^{12}$ and Emmanuel Dias-Neto ${ }^{1 *}$

\begin{abstract}
Gastric cancer (GC) is the fifth most common type of cancer worldwide with high incidences in Asia, Central, and South American countries. This patchy distribution means that GC studies are neglected by large research centers from developed countries. The need for further understanding of this complex disease, including the local importance of epidemiological factors and the rich ancestral admixture found in Brazil, stimulated the implementation of the GE4GAC project. GE4GAC aims to embrace epidemiological, clinical, molecular and microbiological data from Brazilian controls and patients with malignant and pre-malignant gastric disease. In this letter, we summarize the main goals of the project, including subject and sample accrual and current findings.
\end{abstract}

Keywords: Gastric cancer, Epidemiology, Microbiome, Whole exome sequencing, Genomic ancestry, Liquid biopsy, Hereditary gastric cancer, Database

\footnotetext{
* Correspondence: emmanuel@accamargo.org.br

'Lab of Medical Genomics, A.C.Camargo Cancer Center, R. Tagua 440, Sao

Paulo, SP 01508-010, Brazil

Full list of author information is available at the end of the article
}

(C) The Author(s). 2019 Open Access This article is distributed under the terms of the Creative Commons Attribution 4.0 International License (http://creativecommons.org/licenses/by/4.0/), which permits unrestricted use, distribution, and reproduction in any medium, provided you give appropriate credit to the original author(s) and the source, provide a link to the Creative Commons license, and indicate if changes were made. The Creative Commons Public Domain Dedication waiver (http://creativecommons.org/publicdomain/zero/1.0/) applies to the data made available in this article, unless otherwise stated. 
The global distribution of gastric cancer (GC) is heterogeneous, a consequence of worldwide socio-economic disparities as well as of the human-diversity in terms of ancestry and cultural habits, including diet. This heterogeneity is not limited to global incidence but also embraces treatment response, clinical and pathological presentation, and the mutational landscape. This leads to frail translation of the still limited findings from US/Europe/Asia to other countries, including highly admixed and least-studied populations. In an attempt to reduce the GC knowledge-gap, the GE4GAC project, supported by FAPESP (14/26897-0), was implemented in 2016 at the A.C.Camargo Cancer Center (ACCC C) in São Paulo, Brazil. Collaborations are underway with the National Cancer Institute (NIH, USA); Instituto Nacional de Enfermedades Neoplásicas (Peru) and both the VOGAS (www.vogas.eu) and the StoP (www.stop-project. org) consortia. Here, we present our cohort/sample accrual (May 2019), results and aims.

\section{Clinical aspects}

At the ACCCC 130 GC-patients are diagnosed/year. Upfront surgery is performed in $\sim 15 \%$ of early-disease cases. Patients with cT3/T4 tumors and N1,2,3 $(\sim 50 \%)$ usually receive perioperative chemotherapy and surgery $(\sim 70$ gastrectomies/year), after staging laparoscopy. Most cases are discussed in weekly multidisciplinary tumor boards.

Complete pathologic-response is seen in $\sim 12 \%$ of patients. Median follow-up so far was 41 months, and the median survival since neoadjuvant chemotherapy was 73 months. Intention-to-treat analysis showed a 5 -year overall survival of $65 \%$. Clinical research includes the identification of surgical prognostic factors $[1,2]$ and the factors that impact outcome [3-5]. Patients are also invited to join the GE4GAC to investigate different aspects, such as the factors that contribute to $\mathrm{GC}$ development in Brazil, genes relevant for familial GC, predictors of neoadjuvant chemotherapy response and molecular variants that may indicate prognosis. Controls from the endoscopy-sector and the cancerprevention campaign also participate (no-cancer) [6].

\section{Epidemiology}

We investigate associations between GC and demographic characteristics, dietary habits, and lifestyle primarily in subjects living in three geographic areas of Brazil: i) São Pãulo-SP (Southeast), ii) Belém-PA (North) and iii) Fortaleza-CE (Northeast). A total of 1121 subjects (Feb-2016 to May-2019), aged 35-74 years were interviewed, including GC-cases $(N=412$; $\mathrm{C} 16 / \mathrm{ICD}-\mathrm{O} 3)$ and two control groups including subjects recruited during the cancer-prevention campaigns at ACCCC $(N=153)$, or from the Endoscopy Department (no-cancer; $N=556$ ).

\section{Basic and translational GC research}

Collected samples $(N=2856)$ include whole-blood, gastricfluids, biopsies, saliva, and leukocytes, derived from $>400$ cases+controls. These are used to investigate:

i) Gastric Microbiota: We investigate possible links between microbiota and GC, including tumor subtypes/location and neoadjuvant treatment/ response. 16SrRNA sequencing, chosen due to elevated human:eubacteria ratios found in our samples, has been performed for $\sim 460$ samples, indicating $\sim 50$ bacteria present in biopsies and $2 \mathrm{X}$ more for gastric-fluids. Reduced microbiota richness/ diversity in cases was observed compared to controls. Shotgun-metagenomics and metatranscriptomics will be performed for selected samples, together with bacterial cultivation, to determine dead vs. alive bacteria. Virome and fungal populations will also be evaluated. qPCR EBV-analysis $(N=400)$ showed $12.7 \% \mathrm{EBV}+$ in GC-cases and $2.9 \%$ in controls. We recently showed a possible new mechanism of EBV-carcinogenesis where EBV-infection triggers APOBEC3 over-expression and an APOBECmutation signature [7].

ii) Whole exome sequencing (WES) and RNA-Seq: These will give comprehensive views of genomewide alterations pertinent to our population and clinical interests, including immune infiltrates. We aim to have WES for $\sim 400$ patients and RNA-Seq mainly to support treatment-response studies.

iii) Genomic ancestry: Using a set of $\sim 130,000$ Ancestry Informative Markers [8] we found that the average cohort participant has a predominance of Mediterranean (50\%), Northern-European (13.5\%) and Southwest-Asia (12.5\%) ancestries, followed by Sub-Saharan African (4.3\%) and Native-American (3.8\%) (unpublished). Genomic ancestry will be determined for all subjects and correlated against biological and demographic aspects, such as microbiota, diet, mutation profiles and treatment outcome.

iv) Liquid-biopsies: We evaluated the presence of cell-free tumor-derived mutations in gastric washes (GW) collected during endoscopy, comparing mutation levels with biopsies and plasma. Deep sequencing showed enhanced detection when plasma and $\mathrm{GW}$ are evaluated together. GW has been shown to carry mutations not found in biopsies, suggesting tumor heterogeneity/cancerizationfield while providing a tool for monitoring treatmentresponse and disease-recurrence [9].

Other liquid-biopsies approaches investigated are Circulating Tumor Cells (CTCs) and Extracellular Vesicles 
(EVs). EVs-studies have been initiated in-vitro, as a means to study chemotherapy-resistance. Hundreds of patientderived samples have been collected for further studies, including EV-RNA-Seq [10-12] and proteomics [13]. The prognostic-value of CTCs in GC was studied in 88 samples, collected from 55 GC-patients (before/after neoadjuvantchemotherapy) [14]. A clinical trial of trastuzumab given to metastatic GC patients with HER2-negative tumor tissue but HER2 FISH-positive CTCs will start soon.

v) Hereditary GC (HGC): Germline pathogenic variants were found in CDH1, MUTYH, TP53, and ATM in $21 \%$ of HGC-suspect patients. Novel GC-predisposing genes are under study by WES.

\section{RedCap: a structured database}

Data from all enrolled subjects are securely kept in RedCap, a web-based application that currently holds the records from 401 controls and $440 \mathrm{GC}$-cases, including 1632 types of metadata, such as lifestyle $(N=845)$, diet $(N=629)$ and clinicopathological $(N=41)$ variables. The collection of massive amounts of data in a single unified database is a key aspect of GE4GAC, a project that is open for worldwide collaborations.

\section{Abbreviations}

ACCCC: A.C.Camargo Cancer Center; CTCs: Circulating Tumor Cells; EBV: Epstein-Barr virus; EVs: Extracellular Vesicles; FAPESP: Fundação de Amparo à Pesquisa do Estado de São Paulo; GC: Gastric Cancer; GE4GAC: Genomics and Epidemiology for Gastric Adenocarcinomas; GW: Gastric washes; ICD-O3: International Classification of Disease for Oncology; OTU: Operational Taxonomic Unit; WES: Whole Exome Sequencing

\section{Acknowledgements}

The authors acknowledge the support given by the Biobank of the A.C.Camargo Cancer Center and the associated research grants and fellowships provided by FAPESP and CAPES. ED-N, VRM, KJG and DMC are research fellows from Conselho Nacional de Desenvolvimento Científico e Tecnológico (CNPq).

\section{Authors' contributions}

Manuscript writing and GE4GAC coordination: ED-N. Epidemiology: MPC, SVP, VFC, RB, CRN, GPBB, ACCP, CMG, MAF, MSA, TVM, MSB, DMMC, LCC, AMB, AFPLR, LLLS, JCP, TT, PEA, VS, MC, ROS, HBA, AKMA, SVS, DTS, LOM; Bioinformatics: ITS, AMT, BSM, RV, AD, RB, RDCD, IB, MNPS, JCS; EV-studies: VRM, DRC; Familial/early-onset disease: DMC, KMS, GTT; CTC-studies: LTDC, EAA, ABC, BCTF; Immunological studies: KJG, TM; Clinical/Pathological studies: FJC, WLCJr, HCF, LGVC, SD, CALM, VHFJ, RR, LCLC; Endoscopy and sample collection: AGP, CZS; Genomics:TFB, MGA, JMS, GEA, GPB, HCF, LFA, MSS, IKTMT, EE, DNN, ED-N; Microbiome: TFB, MSS, GEA, AMT, DTS, LOM, BSM, AK, SD, PPA, IKTMT, ITS, DNN. Research nurse: LLSA; Data manager: FIAV. All authors have read and expressed their consent to publish this letter.

\section{Funding}

This study was funded by Fundação de Amparo à Pesquisa do Estado de São Paulo (FAPESP), grants 14/26897-0, 18/50013-5; 18/14267-2; 16/117917. FAPESP had no roles in the design of the study and collection, analysis, and interpretation of the data or manuscript writing.

\section{Ethics approval and consent to participate}

The study presented here was approved by the institutional review board (Comitê de Ética em Pesquisa - CEP) of the A.C.Camargo Cancer Center (protocol 2134/15), and all participants signed an approved informed consent form.

\section{Consent for publication}

Not applicable.

\section{Competing interests}

The authors declare that they have no competing interests.

\section{Author details}

'Lab of Medical Genomics, A.C.Camargo Cancer Center, R. Tagua 440, Sao Paulo, SP 01508-010, Brazil. ' International Research Center, A.C.Camargo Cancer Center, R. Tagua 440, Sao Paulo, SP 01508-010, Brazil. ²Department $\mathrm{CIBIO}$, University of Trento, Trento, Italy. ${ }^{4}$ Biochemistry Department, Chemistry Institute, Universidade de São Paulo, São Paulo, SP, Brazil. ${ }^{5}$ Lab. of Bioinformatics and Computational Biology, A.C.Camargo Cancer Center, R. Tagua 440, Sao Paulo, SP 01508-010, Brazil. 'Data Science group, International Research Center, A.C.Camargo Cancer Center, R. Tagua 440, Sao Paulo, SP 01508-010, Brazil. Department of Animal \& Plant Sciences, University of Sheffield, Alfred Denny Building, Sheffield S10 2TN, UK. ${ }^{8}$ Instituto Alfa de Gastroenterologia, Hospital das Clínicas, Universidade Federal de Minas Gerais, Av. Alfredo Balena 110, Belo Horizonte, Minas Gerais 30130-100, Brazil. ${ }^{9}$ Instituto de Ciências Biológicas, Universidade Federal do Pará, Rua Augusto Correa, 01, Belém, PA 66075110, Brazil. ${ }^{10}$ Núcleo de Pesquisas em Oncologia, Universidade Federal do Pará, Rua dos Mundurucus, 4487, Guamá, Belém, Pará 66073-00, Brazil. ${ }^{11}$ Lab. de Genômica e Biologia Molecular, A.C.Camargo Cancer Center, R. Tagua 440, Sao Paulo, SP 01508-010, Brazil. ${ }^{12}$ Epidemiology and Statistics Group, A.C.Camargo Cancer Center, R. Tagua 440, Sao Paulo, SP 01508-010, Brazil. ${ }^{13}$ Laboratório de Biologia Molecular, Hospital Ophir Loyola, Belém, Brazil. ${ }^{14}$ Universidade Federal de Goiás, IPTESP - Instituto de Patologia Tropical e Saúde Pública, Rua 235 SN Setor Leste Universitário, Goiânia, Goiás, Brazil. ${ }^{15}$ Department of Abdominal Surgery, Hospital Araujo Jorge, Rua 239 181 Setor Leste Universitário, Goiânia, Goiás, Brazil. ${ }^{16}$ Instituto de Saúde Coletiva da Universidade Federal da Bahia, Rua Basilio da Gama 316, Canela, Salvador, Brazil. ${ }^{17}$ Instituto do Cancer do Ceará, Rua Papi Júnior, 1222 Rodolfo Teófilo, Fortaleza, CE 60351-010, Brazil. ${ }^{18}$ Clinical Oncology Department, A.C. Camargo Cancer Center, R. Antônio Prudente, 211, São Paulo, SP 01509-010, Brazil. ${ }^{19}$ Department of Pathology, A.C.Camargo Cancer Center, R. Antônio Prudente, 211, São Paulo, SP 01509-010, Brazil.

${ }^{20}$ Endoscopy sector, A.C.Camargo Cancer Center, R. Antônio Prudente, 211, São Paulo, SP 01509-010, Brazil. ${ }^{21}$ Instituto Nacional de Enfermedades Neoplásicas, Av. Angamos 2520, 15038 Surquillo, Peru. ${ }^{22}$ Dept. of Biological and Medical Sciences, Faculty of Health and Life Sciences, Oxford Brookes University, Gipsy Lane, Headington, Oxford OX3 OBP, UK. ${ }^{23}$ Translational Immuno-oncology Group, A.C.Camargo Cancer Center, R. Tagua 440, Sao Paulo, SP 01508-010, Brazil. ${ }^{24}$ Tumor Biology and Biomarkers Group, A.C.Camargo Cancer Center, R. Tagua 440, Sao Paulo, SP 01508-010, Brazil. ${ }^{25}$ Department of Abdominal Surgery, A.C.Camargo Cancer Center, R. Antônio Prudente, 211, São Paulo, SP 01509-010, Brazil.

Received: 19 July 2019 Accepted: 3 September 2019

Published online: 22 October 2019

\section{References}

1. da Costa WL, Coimbra FJF, Ribeiro HSC, Diniz AL, de Godoy AL, de Farias IC, et al. Total gastrectomy for gastric cancer: an analysis of postoperative and long-term outcomes through time: results of 413 consecutive cases in a single cancer center. Ann Surg Oncol. 2015;22(3):750-7.

2. Coimbra FJF, da Costa WL, Ribeiro HSC, Diniz AL, de Godoy AL, de Farias IC, et al. Noncurative resection for gastric Cancer patients: who could benefit? : Determining prognostic factors for patient selection. Ann Surg Oncol. 2016;23(4):1212-9.

3. Costa WL, Coimbra FJF, Fogaroli RC, Ribeiro HSC, Diniz AL, Begnami MDFL, et al. Adjuvant chemoradiotherapy after d2-lymphadenectomy for gastric cancer: the role of n-ratio in patient selection. Results of a single cancer center. Radiat Oncol. 2012;7:169.

4. Fava BEC, da Costa WL, Medeiros MLL, Sonagli M, de Castro Ribeiro HS, Diniz $\mathrm{AL}$, et al. Neoadjuvant intraperitoneal chemotherapy followed by 
radical surgery and HIPEC in patients with very advanced gastric cancer and peritoneal metastases: report of an initial experience in a western single center. World J Surg Oncol. 2018;16(1):62.

5. Coimbra FJF, de Jesus VHF, Ribeiro HSC, Diniz AL, de Godoy AL, de Farias IC, et al. Impact of ypT, ypN, and adjuvant therapy on survival in gastric Cancer patients treated with perioperative chemotherapy and radical surgery. Ann Surg Oncol. 2019; Epub ahead of print.

6. GE4GAC group. Genomics and epidemiology for gastric adenocarcinomas. Appl Cancer Res. 2017;37:7.

7. Bobrovnitchaia I, Valieris R, Drummond RD, Lima JP, Freitas HC, Bartelli TF, et al. APOBEC-mediated DNA alterations: a possible new mechanism of carcinogenesis in EBV-positive gastric cancer. Int J Cancer. 2019 May 15. [Epub ahead of print]

8. Elhaik E, Tatarinova T, Chebotarev D, Piras IS, Maria Calò C, De Montis A, et al. Geographic population structure analysis of worldwide human populations infers their biogeographical origins. Nat Commun. 2014;5:3513.

9. Pizzi MP, Bartelli TF, Pelosof AG, Freitas HC, Begnami MD, de Abrantes LLS, et al. Identification of DNA mutations in gastric washes from gastric adenocarcinoma patients: possible implications for liquid biopsies and patient follow-up. Int J Cancer. 2019;145:1090-8.

10. Amorim MG, Valieris R, Drummond RD, Pizzi MP, Freitas VM, Sinigaglia-Coimbra $R$, et al. A total transcriptome profiling method for plasma-derived extracellular vesicles: applications for liquid biopsies. Sci Rep. 2017 31;7(1):14395.

11. Amorim MG, Branco G, Valieris R, Tarcitano E, Silva IT, Araújo LF, et al. The impact of HER2 overexpression on the miRNA and circRNA transcriptomes in two breast cell lines and their vesicles. Pharmacogenomics. 2019;20(7):493-502

12. Branco GP, Valieris R, Povoa LV, Araújo LF, Fernandes GR, Souza JES, et al. A comparison between SOLiD 5500XL- and ion torrent PGM-derived miRNA expression profiles in two breast cell lines. Genet Mol Biol. 2019; in press.

13. Amorim M, Fernandes G, Oliveira P, Martins-de-Souza D, Dias-Neto E, Nunes D. The overexpression of a single oncogene (ERBB2/HER2) alters the proteomic landscape of extracellular vesicles. Proteomics. 2014;14(12):1472-9.

14. Abdallah EA, Braun AC, Flores BCTCP, Senda L, Urvanegia AC, Calsavara V, et al. The potential clinical implications of circulating tumor cells and circulating tumor microemboli in gastric Cancer. Oncologist. 2019.

\section{Publisher's Note}

Springer Nature remains neutral with regard to jurisdictional claims in published maps and institutional affiliations.

Ready to submit your research? Choose BMC and benefit from:

- fast, convenient online submission

- thorough peer review by experienced researchers in your field

- rapid publication on acceptance

- support for research data, including large and complex data types

- gold Open Access which fosters wider collaboration and increased citations

- maximum visibility for your research: over $100 \mathrm{M}$ website views per year

At $\mathrm{BMC}$, research is always in progress.

Learn more biomedcentral.com/submissions 